\title{
Modifying elastic modulus of two-component polyurethane adhesive for structural hardwood bonding
}

\author{
S. Bockel ${ }^{1,2}$, S. Harling ${ }^{3}$, J. Konnerth ${ }^{2 *}$ (D) P. Niemz ${ }^{1}$, G. Weiland ${ }^{3}$, E. Hogger ${ }^{2}$ and F. Pichelin ${ }^{1}$
}

\begin{abstract}
Subject to this study is the modification of an experimental two-component polyurethane (2C PUR) as an alternative adhesive for structural hardwood bonding. The 2C PUR has been adapted by calcium carbonate as filler to increase its modulus of elasticity with the aim of increasing the modulus analogue to the ones typically observed for classic amino- and phenol based adhesives. The 2C PUR system was compared with a commercial one-component polyurethane (1C PUR) and a phenol resorcinol formaldehyde (PRF) adhesive. The wetting properties of the adhesives were tested in terms of surface tension, polar and dispersive part and contact angle on European beech wood (Fagus sylvatica L.). In addition, adhesive polymer films of 2C PUR were tested for tensile strength and modulus of elasticity (E-Modulus) following ISO 527-1. The adhesives bond performance on beech wood was determined by lap-joints according to EN 302-1 in various climate conditions. The results show that 2C PUR has proper wettability properties on beech wood. Adding 60\% wt filler to the polyol component increased the E-Modulus from $2.3 \mathrm{GPa}(0 \%)$ to $4.4 \mathrm{GPa}$. The tensile strength of the modified 2C PUR polymer films was comparable with the industrial 1C PUR. Tensile shear strength and wood failure percentage of 2C PUR lap-joints were increased by adding filler and met requirements in dry and re-dried conditions according to EN 302-1. However, the addition of filler didn't result in an improvement in wet conditions. The present study shows sufficient performance for bonding hardwood with 2C PUR in dry conditions, while the system still needs to be improvement regarding its performance in humid conditions.
\end{abstract}

Keywords: Adhesives for wood, Polyurethane, Contact angles, Lap-joint, Hardwood

\section{Introduction}

Polyurethane adhesives can be characterized as formaldehyde- and solvent-free and fast bonding at room temperature. Typically, they have a ductile character and a light-colored bonding line. Polyurethanes are created by reaction with different isocyanate and polyol types. Characteristic is the polar urethane-group that enables the adhesion on many adherends [1]. Their crosslinking reaction is a polyaddition, where the hydroxyl groups of the polyol and isocyanate groups lead to urethane formation. The secondary reaction results in allophanate formation

\footnotetext{
*Correspondence: johannes.konnerth@boku.ac.at

${ }^{2}$ University of Natural Resources and Life Sciences, 3430 Tulln an der

Donau, Austria

Full list of author information is available at the end of the article
}

and cross-linking which is controlled by the isocyanate excess. The reaction itself depends to a high degree on the stochiometric ratio between available hydroxyl groups of the polyol and NCO-groups (ISO-Index).

On the search for adhesives with low or no formaldehyde-emission, polyurethane adhesives lead to the continuous replacement of conventional adhesive systems, e.g. in the production of finger jointed solid timber or glulam. Furthermore, cross-laminated timber is nowadays almost exclusively produced with one-component polyurethane adhesive (1C PUR) in Europe [2].

In general, $1 \mathrm{C}$ PUR and two-component (2C PUR) systems are available. While $2 \mathrm{C}$ PUR adhesives cure with their own two adhesive components polyol and isocyanate, 1C PUR adhesive is a prepolymer that cures by the moisture available in the adherend and environment. 
The reaction of water with isocyanate leads to the formation of urea and biuret. One drawback of the moisture induced curing behavior is insufficient curing when falling below certain wood moisture content levels of $8 \%$ [3]. For bonding of structural hardwood elements, few manufacturers are using $1 C$ PUR in combination with an adhesion promoting agent (primer) to enhance the bonding performance, especially for joints exposed to humid conditions. This additional process step often requires a flashing-off time of the water-based primer solution. Recent studies showed that the spread rate of primer application and its concentration are very critical in hardwood bonding and small variations can reduce the primer's effectiveness [4]. Furthermore, the choice of surface preparation can significantly change the bonding performance [5] as well as the primer's efficiency [6].

The 2C PUR system comes with both components separately and is blended only shortly prior to application. This has the great advantage that the resin component can be modified to a higher degree in terms of viscosity, cross-linking density, reaction speed or polarity and the curing process becomes less dependent on the adherend's moisture content. Furthermore, the higher flexibility in modifying the polyol component may substitute the process step of primer application, as needed for 1C PUR. Until now, the use of $2 C$ PUR is mainly limited to the use of bonding thread rods into solid wood beams. One new application is the butt joint gluing of cross-laminated timber from softwood [7]. Only few studies have been dealing with 2C PUR in structural surface bonding, but with the restriction of testing only mechanical performance in dry conditions [8]. Own studies have been investigating the influence of extractives on the curing properties and performance of 2 C PUR $[9,10]$.

However, polyurethane adhesives still tend to show deficits when bonding wood species different from Norway spruce, especially when bonding some hardwoods $[11,12]$ and when the bond is exposed to high moisture contents. An obvious difference to classical structural adhesives such as phenol resorcinol formaldehyde (PRF) and melamine urea formaldehyde (MUF) adhesives [13] seems to be the significantly lower elastic modulus (E-Modulus) of PUR adhesives. Therefore, a mechanical modification aiming for an increase of modulus analogue to these classic amino- and phenol based adhesives seems to be one strategy.

The mechanical properties of polyurethane adhesives are mainly determined by the prepolymer composition, but bonding performance is often influenced by additives and fillers [14]. Very critical in polyurethane modification is the coordination of isocyanate content and functionality [15]. Shear strength of bonded wood was increased by a higher number of hard segments in polyurethane.
Therefore, Clauß et al. [16] postulated hardness as the main-tweaking point in adhesive development. Harling et al. [17] was able to select suitable polyol components based on their hardness to increase mechanical performance of experimental polyurethane adhesives.

Hypothesis to this study is, that the modification of 2C PUR by a filler results increased E-Modulus of the adhesive and therefore enables the adhesive to surpass standard requirements following EN 302-1 [18] on beech wood in dry and wet conditions.

Following experiments were undertaken in this study:

1) Comparison of wetting properties of the adhesives in terms of surface tension and polarity on European beech wood by means of free surface energy and contact angle between different adhesive systems.

2) Investigation of the effect of filler content in the resin component $(0-60 \% \mathrm{wt})$ on the mechanical properties of thin 2C PUR films by means of tensile strength and E-Modulus in comparison to PRF.

3) Influence of filler content in the resin component (0-60\% wt) on the mechanical performance of lapjoints on beech wood following EN 302-1.

4) Comparison of tensile shear strength and wood failure percentage of beech wood bonds using different adhesives in different climate conditions (EN 302-1).

\section{Materials and methods \\ Wood}

Lamellas of European beech wood [Fagus sylvatica L.] with an average density of $689 \pm 46 \mathrm{~kg} / \mathrm{m}^{3}$ and a growth ring angle between 30 and $90^{\circ}$ as described in EN 302-1 were selected from one lot without any irregularities. The lamellas were planed for lap-joint manufacture to $10 \mathrm{~mm}$ thickness and subsequently conditioned in standard climate $\left(20{ }^{\circ} \mathrm{C} / 65 \% \mathrm{RH}\right)$ until an approximate equilibrium moisture content of $12 \%$ was reached. The determination of free surface energy of beech wood and contact angle of adhesives was carried out on one selected lamella at its radial plane with a freshly planed surface.

\section{Adhesives}

The selected adhesives for this study and some of their properties and process parameters are shown in Table 1. All polyurethane adhesives were provided by the adhesive manufacturer Collano AG (Sempach Station, Switzerland). The resin component of the $2 \mathrm{C}$ PUR was an experimental type polyester-polyether polyol (molecular weight $300 \mathrm{~g} / \mathrm{mol}$ ) with $100 \%$ solid content, not containing any solvent or latex emulsion. Dry 
Table 1 Overview of adhesives, selected properties and processing parameters

\begin{tabular}{|c|c|c|c|}
\hline \multirow[t]{2}{*}{ Adhesive } & 2C PUR & 1C PUR & PRF \\
\hline & Collano experimental type & Collano RP 2760 & $\begin{array}{l}\text { Dynea Aerodux } \\
185 \text { RL/HRP } 155\end{array}$ \\
\hline Ratio weight (resin/hardener) & $2.45: 1$ & - & $1: 0.2$ \\
\hline Viscosity (mPas) @ $20^{\circ} \mathrm{C}$ & 40,000 & $20,000-30,000$ & $8000-10,000$ \\
\hline Max. open time (min) @ $20^{\circ} \mathrm{C}$ & 60 & $<60$ & $8-10$ \\
\hline Application $\left(\mathrm{g} / \mathrm{m}^{2}\right)$ one side & 200 & 160 & 450 \\
\hline Closed assembly time (min) & 0 & 0 & 30 \\
\hline Pressure (MPa) & 0.8 & 0.8 & 0.8 \\
\hline Press time (h) & 10 & 10 & 10 \\
\hline
\end{tabular}

grounded calcium carbonate (Millicarb OG) powder with an average diameter of $3 \mu \mathrm{m}$ and a size distribution between 0.05 and $12.5 \mu \mathrm{m}$ was used as filler. $2 \mathrm{C}$ PUR variants with $0,15,30 \%$ and $60 \%$ filler content in the polyol component were produced.

The isocyanate component was Desmodur VK 10 from Covestro AG (Leverkusen, Germany), a mixture of diphenylmethane-4,4' -diisocyanate (MDI) with isomers and higher functional homologues (PMDI) with free reactive isocyanate groups of $31.5 \%$ (NCO).

The ISO index, describing the ratio between the isocyanate groups of the isocyanate component and hydroxyl groups of the polyol obtained 110 and should ensure saturation with isocyanate and a high crosslinking density.

The used type and amount of filler is a result of a previous selection process (not reported here), where different filler types, and amounts have been investigated to control the even adhesive flow into the interphase of wood and prevent a starvation of the bond line. To further support the adhesive in the bonding line, fumed silica was added to increase the surface area of the adhesive and prevent a deposition of the adhesive in the interphase. Other additives such as chain extender of low molecular weight were used to improve adhesion performance.

A commercial 1C PUR adhesive for structural wood bonding and accredited according to EN 15425:2017 (Type I) [19] on spruce, fir and pine was chosen to evaluate and compare the $2 \mathrm{C}$ PUR performance. In addition, the PRF Aerodux 185 provided by Dynea AS (Krems, Austria) was selected as an established reference for structural wood bonding [1]. The viscosities were measured in accordance with the Brookfield method with shear rates of $20 \mathrm{rpm}$.

Due to the fact, that the 2 C PUR variant is an experimental type, the adhesive application was selected more conservative with a spread rate of $200 \mathrm{~g} / \mathrm{m}^{2}$, while the spread rate of the established adhesives was selected according to the manufacturers recommendations.

\section{Determining wetting properties}

All measurements for determining wetting properties were carried out with the device Krüss Drop Shave Analyzer DSA 30 (Hamburg, Germany) at ambient temperature. The method following Owens, Wendt, Rabel and Kaelbe (OWRK) [20] was used to calculate the free surface energy of a solid from its contact angle with different liquids. This method further divides free surface energy into a polar and dispersive part.

The free surface energy and contact angle of European beech (Fagus sylvatica L.) was determined according to DIN 55660-2 [21] using static procedure. Prior experiments (results not shown) only revealed a minor difference in contact angle between tangential and radial plane of beech wood. Hence, experiments were conducted on the radial plane only. The contact angle of the adhesives on beech wood was tested by the same procedure as for the individual test liquids. For all testing liquids and adhesives, a minimum of 10 drops were tested. Purified water (Milli-Q ${ }^{\circledR}$ ) was obtained by the device Q-Gard 2 (Merck \& Cie, Darmstadt, Germany). The remaining testing liquids shown in Table 2 were obtained from Sigma Aldrich in analytical grades (Buchs, Switzerland).

Table 2 Surface tension and its polar and disperse part of liquids to determine the wetting properties of surfaces according to DIN 55660-2 [21]

\begin{tabular}{lllll}
\hline Chemicals & $\begin{array}{l}\text { Surface } \\
\text { tension } \\
\boldsymbol{\sigma}_{\mathbf{I}} \\
(\mathbf{m N} / \mathbf{m})\end{array}$ & $\begin{array}{l}\text { Disperse part } \\
\boldsymbol{\sigma}_{\mathbf{1}}^{\mathbf{d}} \\
(\mathbf{m N} / \mathbf{m})\end{array}$ & $\begin{array}{l}\text { Polar part } \\
\boldsymbol{\sigma}_{\mathbf{1}}^{\mathbf{m}} \\
(\mathbf{m N} / \mathbf{m})\end{array}$ & Purity (\%) \\
\hline Distilled water & 72.8 & 21.8 & 51.0 & - \\
Diiodomethane & 50.8 & 50.8 & 0.0 & 99.9 \\
Ethylene glycol & 47.7 & 30.9 & 16.8 & 99.5 \\
Glycerin & 64.0 & 34.0 & 30.0 & 98.0 \\
\hline
\end{tabular}


As required by the standard, they obtain a wide range of polarity and one of the liquids obtained a polar part of 0 . The drops of about $10 \mu \mathrm{l}$ were analyzed by averaging ten measurements performed within $10 \mathrm{~s}$. Before the drops were given $2 \mathrm{~s}$ after contact with the adherend to form a stable drop. A total amount of 10 drops was measured for each adhesive type with a total amount of 10 measurements for each drop. In case of PRF, the drops were measured $10 \mathrm{~min}$ after initial blending to prevent the formation of bubbles during testing.

Surface tension of adhesives was analyzed by the pendant drop method according to DIN 55600-3 [22]. Disposable syringes with steel cannula $(1.8 \mathrm{~mm} \varnothing)$ were used to ensure proper drop formation. When the drop was stable, 10 measurements were taken within one second. To obtain the polar and dispersive part of the surface tension, the free surface energy of a reference sample without polar compound, in this study solid silicone $\left(\sigma_{\mathrm{s}}=21.6 \mathrm{mN} / \mathrm{m}\right)$, was determined. The contact angle is determined and the disperse component calculated following the method of OWRK:

$$
\sigma_{1}^{\mathrm{d}}=\frac{(1+\cos \theta)^{2} * \sigma_{1}^{2}}{4 \sigma_{\mathrm{s}}}
$$

$\theta$ mean value of contact angle between the liquid and the reference solid

$\sigma_{l}$ surface tension of the liquid

$\sigma_{\mathrm{s}}$ free surface energy of the reference solid

With the disperse part of the surface tension known, the polar part is calculated as follows:

$$
\sigma_{1}^{\mathrm{p}}=\sigma_{1}-\sigma_{1}^{\mathrm{d}}
$$

$\sigma_{1}$ surface tension of the liquid

$\sigma_{1}^{\mathrm{d}}$ dispersive part of the surface tension of the tested liquid

\section{Longitudinal tensile shear strength and wood failure on beech wood}

Conditioned beech wood lamellas of $10 \mathrm{~mm}$ thickness were planed with fresh knives to $5 \mathrm{~mm}$ thickness within $30 \mathrm{~min}$ prior to bonding, cut to the required size and cleaned with compressed air. The adhesives were applied manually by a metal spatula in accordance with the manufactures recommendation as shown in Table 1 . The application quantity of the adhesive was controlled by a scale. To ensure precise pressure distribution, the lamella pairs were stacked into a holding device before entering the hydraulic press (Lindenberg, Altendorf, Switzerland).

The time between the stacking of the lamellas into the holding device and the application of pressure was around 2 min.

The lamellas were pressed for $10 \mathrm{~h}$ with $0.8 \mathrm{MPa}$ pressure at ambient temperature. After pressing, samples were stored in standard climate $\left(20{ }^{\circ} \mathrm{C} / 65 \% \mathrm{RH}\right)$ for 3 weeks to ensure full curing and sample conditioning. Then, samples were cut to size and treated according to EN 302-1 using the conditions described in Table 3. Subsequently, they were tested in tensile shear mode in a universal testing machine Zwick/Roell $30 \mathrm{kN}$ (Ulm, Germany). Load was applied in displacement-controlled mode using a constant cross head speed between of $2 \mathrm{~mm} / \mathrm{min}$ resulting in failure between 30 and $90 \mathrm{~s}$. The wood failure percentage were determined visually in $10 \%$-steps.

Statistical analysis was preceded with a single factor variance analysis (ANOVA with 95\% confidence interval) and a post hoc least significant difference to enable statistical comparison of the variants.

\section{Polymer films}

The filler content was introduced by mixing different amounts into the polyol by a Vollrath Mixer (Hürth, Germany) at $750 \mathrm{rpm}$ for $15 \mathrm{~min}$ followed by $15 \mathrm{~min}$ at $300 \mathrm{rpm}$ and $50 \mathrm{mbar}$ for evacuation of air. Variants with around $60 \%, 30 \%$ and $15 \%$ wt. were produced as well as a variant with no filler for comparison.

Cast films were prepared at ambient temperature. The liquid adhesives were applied on polyethylene foil with a defined thickness of ca. $150 \mu \mathrm{m}$ by a film application device. For comparison, adhesive films of PRF were tested as well. Before the films were fully cured, samples were cut out using a bone-shaped punch-cutter after $3-4 \mathrm{~h}$ to a specimen size of $120 \mathrm{~mm}$ length with $25 \mathrm{~mm}$ wide holders at the end. The gauge area obtained a width

Table 3 Definitions of sample treatment for tensile shear strength according to EN 302-1 [21]

\begin{tabular}{ll}
\hline Treatment & Sample conditioning \\
\hline A1 & Testing after 7 days conditioning in standard climate $20^{\circ} \mathrm{C} / 65 \%$ relative humidity \\
A2 & 4 days storage in cold water $(20 \pm 5){ }^{\circ} \mathrm{C}$, testing in wet state \\
A4 & $6 \mathrm{~h}$ storage in boiling water, $2 \mathrm{~h}$ submerged in cold water $(20 \pm 5){ }^{\circ} \mathrm{C}$ \\
A5 & $6 \mathrm{~h}$ storage in boiling water, $2 \mathrm{~h}$ submerged in cold water $(20 \pm 5){ }^{\circ} \mathrm{C}$, recondi- \\
& tioning until reaching initial mass, testing in dry state \\
\hline
\end{tabular}


of $6.3 \mathrm{~mm}$ and a length of $35 \mathrm{~mm}$. Specimens with inconsistent thickness, cracks, bubbles or other irregularities were sorted out. Films were subsequently stored in standard climate for 3 weeks to ensure full curing. Afterwards, they were tested in a universal testing machine Zwick/ Roell $30 \mathrm{kN}$ (Ulm, Germany) with a $500 \mathrm{~N}$ load cell following EN ISO 527-1 [23]. The strain in longitudinal and transversal direction was measured with a Videoextensometer (Zwick Roell, Ulm, Germany). Test speed was set to $0.75 \mathrm{~mm} / \mathrm{min}$ between 0.05 and $0.25 \%$ strain, representing the region to determine the E-Modulus. After that, the test speed was increased to $5 \mathrm{~mm} / \mathrm{min}$ until failure was reached and the tensile strength was obtained for the 2C PUR films. Due to the brittle character of PRF, a test speed to failure of $2 \mathrm{~mm} / \mathrm{min}$ was chosen as proposed by Kläusler et al. [24].

\section{Results and discussion}

\section{Wetting properties of beech wood and adhesives}

The wetting properties on the radial plane of European beech wood (Fagus sylvatica L.) were characterized by contact angle, free surface energy and its polar and disperse part. For water, the contact angle directly after planing was $56.1 \pm 4.5^{\circ}$ and changed only insignificantly for $24 \mathrm{~h}$ old surfaces to $56.8 \pm 4.8^{\circ}$. The calculated free surface energy, considering contact angle results of all four test liquids using the model of OWRK, resulted in $50.25 \pm 12.7 \mathrm{~mJ} / \mathrm{m}^{2}$ for fresh beech and $52.8 \pm 6.8 \mathrm{~mJ} /$ $\mathrm{m}^{2}$ after $24 \mathrm{~h}$. Due to the high standard deviation of the surface energy, the small increase in surface energy does not seem to be meaningful. Although the magnitude of the surface free energy is in the range of earlier measurements, typically ageing of wood surfaces results in decreasing surface energy [25]. The polar part of the beech surface directly after planing obtained $8.65 \mathrm{~mJ} /$ $\mathrm{m}^{2}$ and the disperse part $41.6 \mathrm{~mJ} / \mathrm{m}^{2}$. After $24 \mathrm{~h}$, the disperse part increased to $45.27 \mathrm{~mJ} / \mathrm{m}^{2}$ and the polar part decreased slightly to $7.53 \mathrm{~mJ} / \mathrm{m}^{2}$.

The surface tension and the disperse and polar part of the tested adhesives are shown in Fig. 1.

The surface tension of the 1C PUR was lower than for the $2 \mathrm{C}$ PUR. The $2 \mathrm{C}$ PUR system obtained a surface tension of $38.2 \mathrm{~mJ} / \mathrm{m}^{2}$ with a polar part of $11.4 \mathrm{~mJ} / \mathrm{m}^{2}$ and a disperse part of $26.8 \mathrm{~mJ} / \mathrm{m}^{2}$. However, the $2 \mathrm{C}$ PUR adhesive showed a higher disperse component in comparison with the 1C PUR adhesive. Noticeable was further the higher standard deviation of the 2C PUR in comparison with the other adhesives, which might be a result of the ongoing reaction of the adhesive. Analyzing the $2 \mathrm{C}$ PUR components it becomes evident, that the hardener contains a larger disperse part than the resin component. The water-based PRF obtained a surface tension comparable with 1C PUR. Its high disperse part may be explained by its solid content of 55-61\%. Yang and Frazier [26] showed that fillers can led to a significant reduction in surface tension at the example of phenol formaldehyde adhesives.

To determine the wetting of the used adhesives on beech wood, contact angles were measured. The contact angle of adhesives applied on beech wood are depicted in Fig. 2. The direct comparison of adhesive systems should be considered with care, as additionally to the chemical nature different technological properties of the adhesive e.g. viscosity or density may bias the values measured on the porous wood substrate.

In comparison, the modified $2 \mathrm{C}$ PUR system ranged similar to the 1C PUR. Furthermore, the contribution of both components of the 2C PUR system were tested separately. While the resin revealed a contact angle of $86^{\circ}$, the hardener obtained only $26^{\circ}$. Noticeable was the

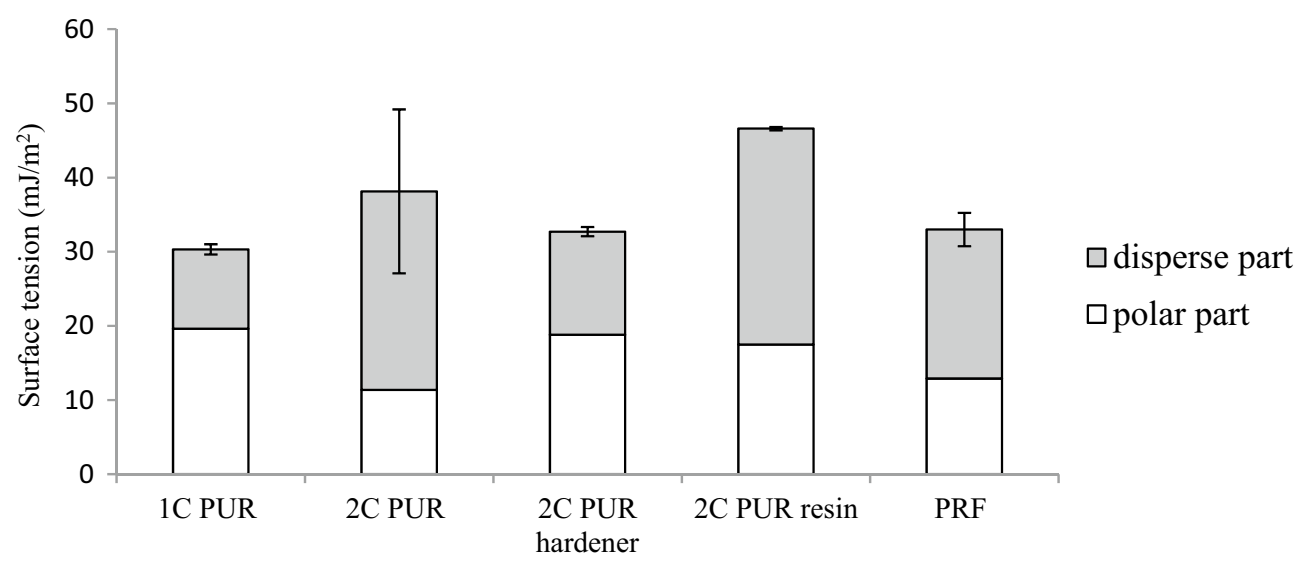

Fig. 1 Disperse and polar parts of surface free energy of different adhesive systems and adhesive components ( $n=10$ ) according to OWRK method at room temperature in liquid state 


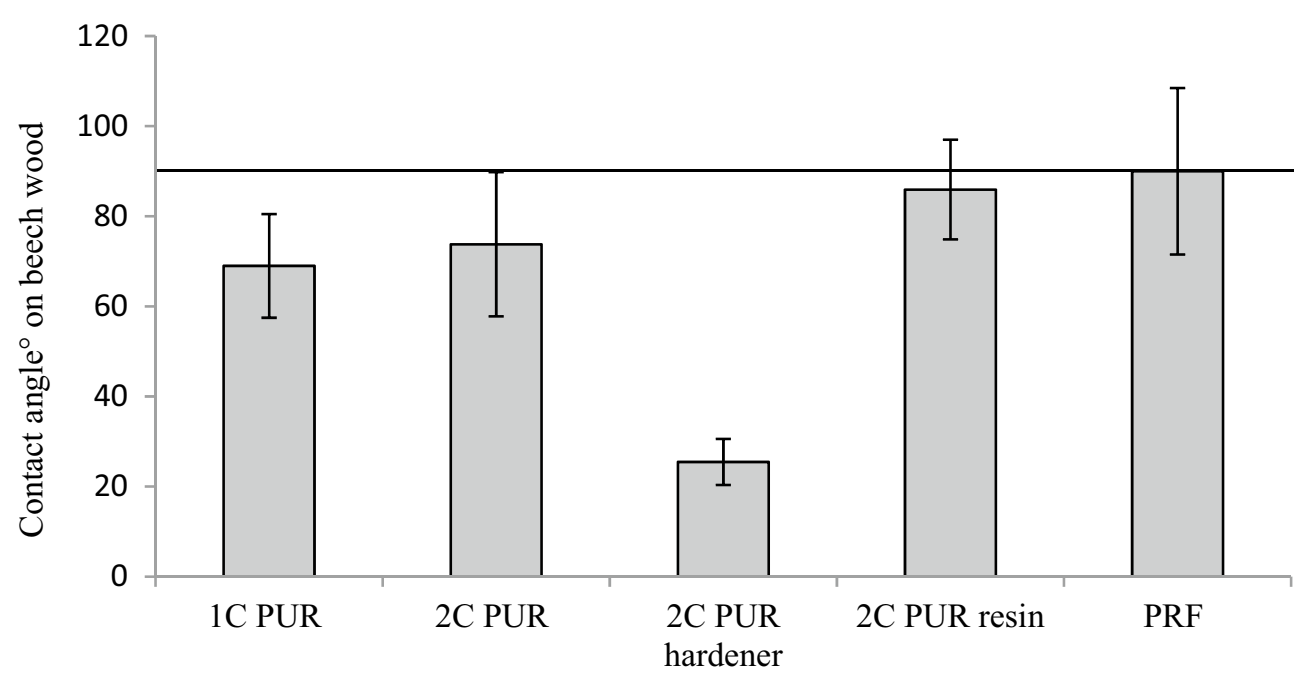

Fig. 2 Mean value and standard deviation of contact angle of adhesives and adhesive components on fresh planed beech wood on its radial plane $(n=10)$ at room temperature in liquid state. Horizontal line marks the border for favorable wetting $\left(>90^{\circ}\right)$

high contact angle of PRF on beech wood with ca. $90^{\circ}$, while having a low surface tension of only $20.8 \mathrm{~mJ} / \mathrm{m}^{2}$. According to Habenicht [27] a contact angle $\geq 90^{\circ}$ is characterized with non-favorable wetting performance.

It has to be considered that analyzing the adhesives wettability on wood, its liquid penetration and spreading on the wood surface changes the contact angle as a function of time as described by Shi and Gardener [28]. Therefore, these results represent a brief moment of the adhesives wetting performance. In case of PRF, a study of Stehr et al. [29] attested for example a decrease in contact angle after a short while.

\section{Mechanical properties of adhesive films}

The results of tensile strength opposed to E-Modulus for adhesive films are depicted in Fig. 3.

The 2C PUR variant without filler content demonstrated a high tensile strength of $47 \mathrm{MPa}$ and a corresponding E-Modulus of $2.3 \mathrm{GPa}$. Adding 15\% filler to the adhesive reduced the tensile strength considerably to $33 \mathrm{MPa}$ and the E-Modulus to $1.7 \mathrm{GPa}$. A filler content

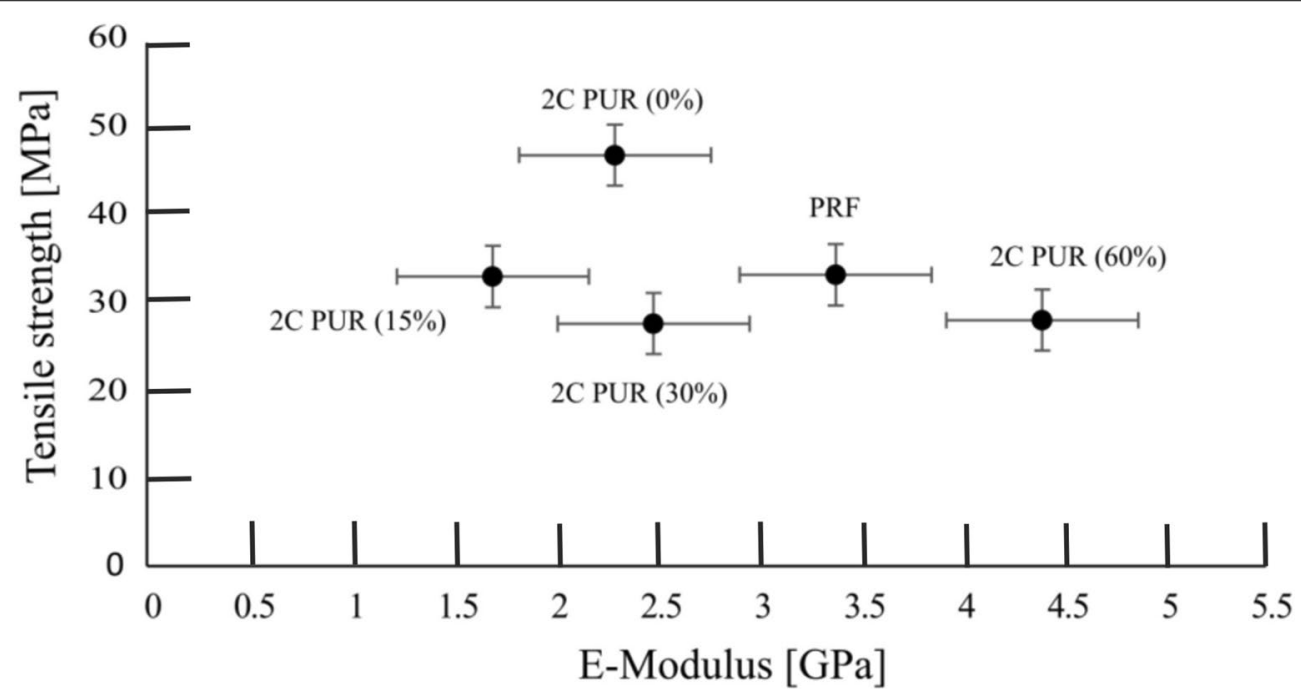

Fig. 3 Tensile strength and E-Modulus of adhesive films in standard climate $(n=10)$. For 2C PUR the amount of filler in the resin component is shown in wt $\%$ 
of $30 \%$ showed a slightly lower tensile strength of $28 \mathrm{MPa}$ and an increase in E-Modulus $2.5 \mathrm{GPa}$. The variant with $60 \%$ filler content revealed $28 \mathrm{MPa}$ tensile strength and a significantly increased E-Modulus, compared to the unmodified reference, of 4.4 GPa. Noticeable was the high standard deviation for the various variants. Prior investigations by scanning electron microscopy showed a homogenous distribution of the filler in the glue line (results not shown). Hence, the observed deviation may not be explained by a local agglomeration or uneven distribution of the filler. In comparison, the PRF obtained a tensile strength of $33 \mathrm{MPa}$ and an E-Modulus of 3.4 GPa which was in accordance with findings of the literature [24] and similar to the 2C PUR variants with $60 \%$ wt filler content.

Kläusler et al. [24] further reported for commercial 1C PUR systems tensile shear strength between 24 and $27 \mathrm{MPa}$ and an E-Modulus from 1.0 to $1.1 \mathrm{GPa}$ at $20^{\circ} \mathrm{C}$ and $65 \% \mathrm{RH}$. Therefore, commercial 1C PUR systems obtained a lower E-Modulus and tensile strength than the present experimental 2C PUR. The lower E-Modulus was further confirmed by Clauss et al. [16] and Konnerth et al. [30].

\section{Tensile shear strength and wood failure percentage}

The results of tensile shear strength (TSS) and wood failure percentage (WFP) of the 2C PUR variants with different filler contents $(0-60 \% \mathrm{wt})$ in their resin component can be seen in Fig. 4. Testing in dry conditions (A1) revealed that the variants with 0 and $60 \%$ filler content surpassed the standards requirement of $10 \mathrm{MPa}$, while

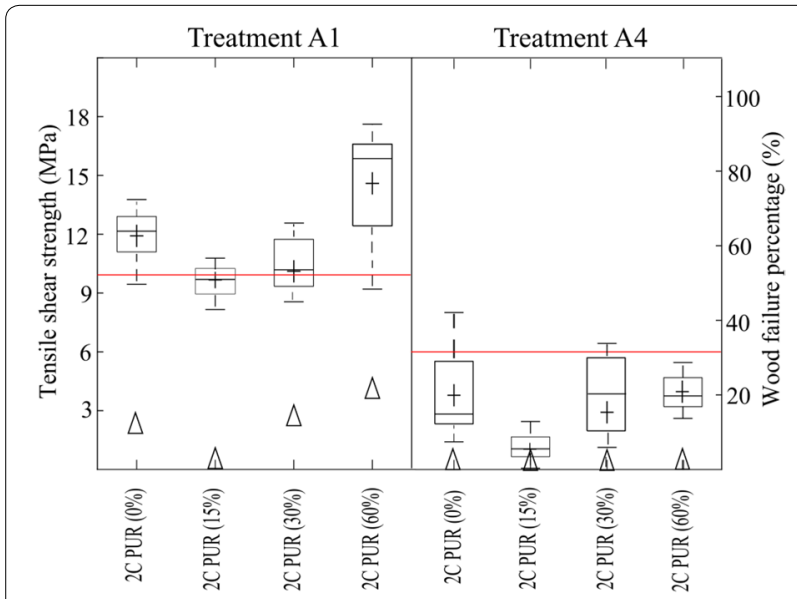

Fig. 4 Boxplots of tensile shear strength (mean value marked as cross) and wood failure (triangle) after treatment $\mathrm{A} 1$ and $\mathrm{A} 4$ for $2 \mathrm{C}$ PUR with different amounts of filler in the resin component $(0,15,30$, $60 \%$ ). Boxplots indicate median, interquartile range and minimum and maximum are shown as whiskers. Red line marks standards requirement for each treatment according to EN 302-1 the variants with $15 \%$ and $30 \%$ filler content slightly fell below it. Within the tested variants, the variant with $60 \%$ showed the highest TSS with a mean value of $14.5 \mathrm{MPa}$, while the WFP was slightly higher than the other variants with around $30 \%$. In wet conditions (A4), no variant was able to surpass the standards requirement of $6 \mathrm{MPa}$. Inbetween the variants different deviations were observed. All variants showed a complete absence of WFP.

The results of TSS and wood WFP of lap joints bonded with different adhesives and solid beech wood of similar geometry as a reference are shown in Fig. 5. For the commercial 1C PUR Collano RP 2760, the test results of the accreditation of the Material Testing Institute of the University of Stuttgart (report not published) were used. The accreditation was carried out with the same parameters as in the present study. Testing in dry conditions (treatment A1) revealed, that

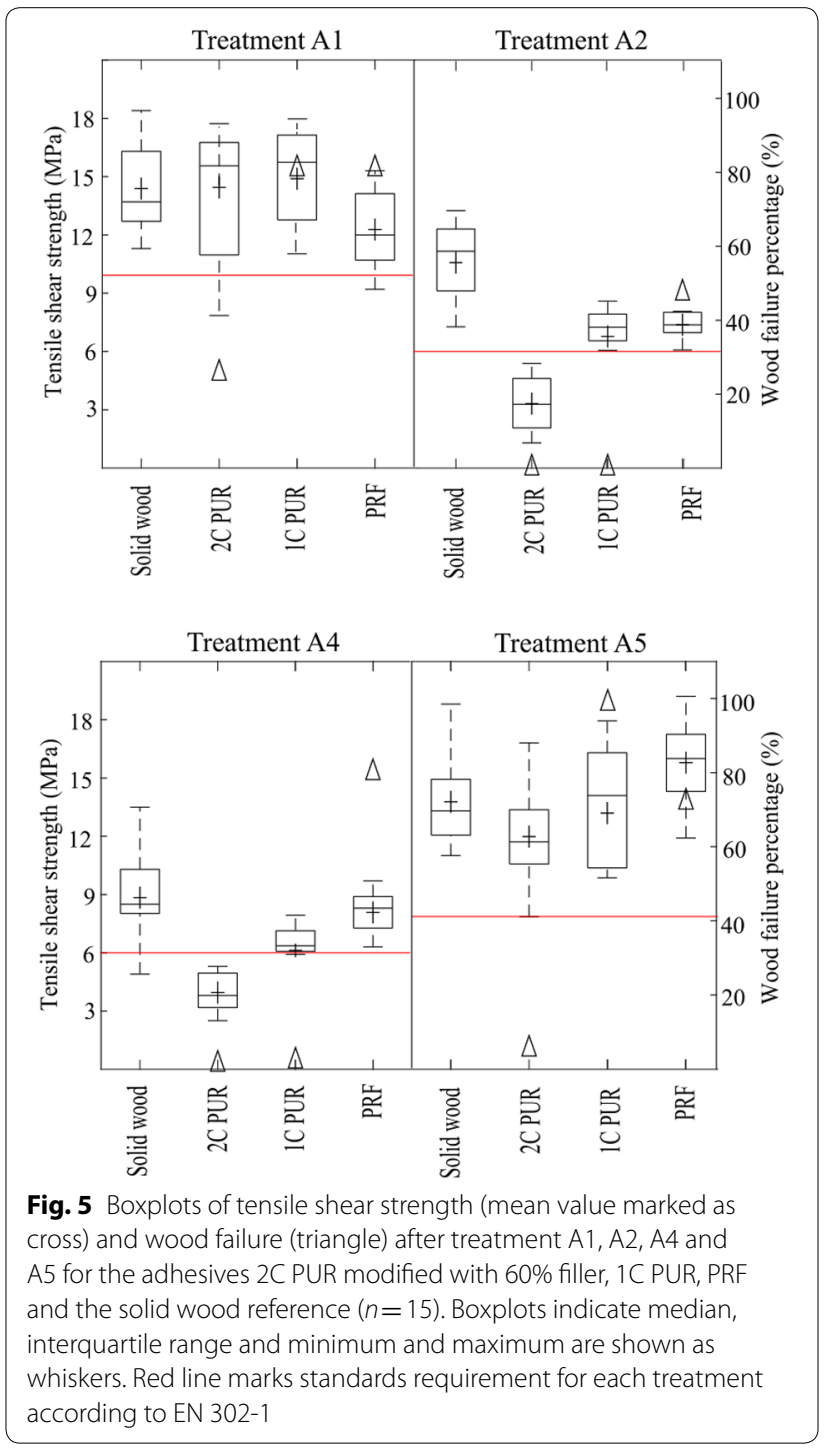


all variants surpassed the standards requirement of $10 \mathrm{MPa}$. Between the three adhesives, no significant difference in TSS was found.

While the 2C PUR including $60 \%$ of filler showed only low WFP, 1C PUR and PRF obtained high WFP of around $80 \%$. After storing specimens in water for four days (treatment A2), a considerable reduction in both, tensile shear strength and WFP was observed for all adhesive systems including the solid wood reference. 1C PUR and PRF were able to exceed the standards requirement of $6 \mathrm{MPa}$, while the 2C PUR performed significantly lower. Both polyurethane adhesives (1C and $2 \mathrm{C}$ ) demonstrated a lack of WFP, while it was reduced to $50 \%$ for the PRF bonded joints. After treatment A4, the solid wood reference was further reduced in comparison to treatment A2. A significant difference was found between the two polyurethane adhesives, while PRF and 1C PUR could pass the standard requirement. Similar to treatment A2, both PUR versions revealed a total absence of WFP, while PRF maintained again a high WFP of $90 \%$.

When comparing PUR and PRF, it has to be mentioned that molecules of low molecular weight of the PRF are typically expected to penetrate the cell wall and are therefore typically able to stabilize the interphase region [31]. In addition, PRF and PUR adhesives are typically very different in their mechanical properties.

All samples re-gained their original dry strength after treatment A5. While all adhesives surpassed the standard requirements, especially the values for WFP differed significantly from each other.

In terms of tensile shear strength, the beech wood lap-joints revealed an adequate performance of the 2C PUR system in dry (A1) and re-dried (A5) conditions and achieved standard requirements for these treatments according to EN 302-1. Both tested polyurethane adhesives revealed a lack of WFP, but only 2C PUR showed adhesion deficits when tested in wet conditions (A2 and A4). In contrast the 1C PUR passed the standards requirements in wet conditions.

While the WFP of PRF changed only slightly for the different treatments, the 1C PUR showed slight elevated WFP in dry conditions only. In contrast, the $2 \mathrm{C}$ PUR showed comparably low WFP values also in both dry conditions (A1, A5).

The absence of WFP in wet conditions for the tested polyurethane adhesives and especially the $2 \mathrm{C}$ PUR indicates an adhesion failure at the interface of the adherend. The lower performance of polyurethane adhesives on hardwood in comparison to PRF was also observed for a range of other polyurethane based systems when no primer was applied [6].

\section{Discussion}

The wetting properties of the experimental $2 \mathrm{C}$ PUR system were similar to the tested 1C PUR adhesive in terms of surface tension, polar and disperse part as well as contact angle on beech wood. It can be concluded that 2C PUR fulfils requirements for spontaneous wetting according to Habenicht [27] with the adhesive having a lower surface tension than the surface free energy of the adherend beech wood.

The good wetting properties of $2 \mathrm{C}$ PUR enable a surface-wide and close contact on beech wood in combination with the development of a consistent bonding line. Interestingly the sufficient wetting in liquid state could not be sufficiently transferred to the cured state, as evident from the complete absence of WFP for this adhesive.

Studies of Obersriebnig et al. [32] showed that polyurethane adhesives have a higher adhesion on more hydrophobic wooden surfaces, while a water-based adhesive obtained higher adhesion on more hydrophilic surfaces. Subsequently, the 2C PUR might have some disadvantages in general with its, in comparison to $1 C$ PUR, lower polarity of the adhesive system. It remains questionable if a modification of the PUR towards higher polarity and consequently reduced wettability would result in improved bonding performance-or other factors dominate the superior performance of the PRF adhesive.

The modification of $2 \mathrm{C}$ PUR by a high amount of filler led to an increase in E-Modulus, going along with a reduction in tensile strength of adhesive films close to the level of PRF. Similar to other studies, film properties of the 2C PUR didn't perform linear with the addition of filler content as shown in other studies [33,34].

The modification by filler further showed an increase of TSS in dry conditions, which was in accordance with findings of Clauß et al. [14]. However, this improvement was not transferred to the performance in wet conditions (A4). In contrast Harling et al. [17], were able to reduce the delamination resistance of $2 \mathrm{C}$ PUR on beech wood according to EN 14080 [35] from $100 \%$ to $30 \%$ by varying polyol and hardness. This was mainly explained by the reduction of adhesive flow into the cell lumina of the interphase, as observed in a study of Clauß et al. [14]. The latter authors also showed that the positive effect of filler on the bond can be reduced with an increasing moisture content. This appeared to be more important for the tensile shear strength than for the delamination test. In addition, the wood failure percentage of the $2 \mathrm{C}$ PUR variant was noticeable high in comparison with PRF and the commercial 1C PUR system.

The recent modifications of the experimental $2 \mathrm{C}$ PUR showed to be partly successful in comparison with bonding properties of commercial $1 \mathrm{C}$ PUR when no adhesion promoting agent (primer) was used [6]. As the 
mechanical properties of the adhesive polymer itself can be modified by filler addition to similar magnitude as for a conventional adhesive, the low performance in wet conditions together with the absence of WFP is assumed to have its origin in adhesion deficits.

The approach to increase the E-Modulus of $2 \mathrm{C}$ PUR using a filler was successful, while its effect on woodbond performance was limited. It can be expected that especially when moisture is induced, the performance of the $2 \mathrm{C}$ PUR at the interface lacks in adhesion and therefore reduces the WFP. Hence the E-Modulus of the system can not be considered the most critical factor in adhesive formulation.

While the process parameters have already been tested sufficiently, following studies shall focus on the selection of pre-polymers as well as a wide range of additives and fillers to address this problem. One possible continuation of further research may be the implementation of the function of the primer into the polyol component of the $2 \mathrm{C}$ PUR to enhance the adhesion, especially in wet state.

\section{Conclusion}

The results of the present study show that the modified 2C PUR system has proper wetting properties on beech wood. The tensile strength of the bulk adhesive of the $2 \mathrm{C}$ PUR variant with $60 \%$ wt filler content is well in range of common PRF adhesives, while due to modification by filler a significantly higher E-Modulus could be reached with the $2 \mathrm{C}$ PUR. The modified $2 \mathrm{C}$ PUR with $60 \%$ filler was improved in comparison to lower filler contents and surpassed standard requirements of lap-joints in dry (A1) and re-dried (A5) conditions according to EN 302-1, but not in wet conditions (treatment A2 \& A4).

As the mechanical properties of the adhesive polymer itself can be modified by filler addition to a wide range, the low performance in wet conditions together with the absence of WFP is assumed to have its origin in adhesion deficits. Further studies have to address the adhesion deficits to adjust the $2 \mathrm{C}$ PUR system accordingly.

\section{Abbreviations \\ 1C PUR: One-component polyurethane adhesive; 2C PUR: Two-component polyurethane adhesives; PRF: Phenol resorcinol formaldehyde adhesive; TSS: Tensile shear strength; WFP: Wood failure percentage.}

\section{Acknowledgements}

The authors thank the Swiss Innovation Agency Innosuisse for the financial support.

\section{Authors' contributions}

SB carried out all experiments and wrote the manuscript. EH performed the experiments regarding the wetting performance of the adhesives. SH and GW produced and modified the adhesive. JK supervised a part of the experiments and revised the manuscript. PN and FP discussed the results with SB and revised the manuscript. All authors read and approved the final manuscript.

\section{Funding}

This work was supported by the Swiss Innovation Agency Innosuisse (Project No. 18063.1).

\section{Availability of data and materials}

The data generated or analyzed during this study are available from the corresponding author upon request.

\section{Competing interests}

On behalf of all authors, the corresponding author states there is no conflict of interest.

\section{Author details}

${ }^{1}$ Bern University of Applied Sciences, 2500 Biel, Switzerland. ${ }^{2}$ University of Natural Resources and Life Sciences, 3430 Tulln an der Donau, Austria. ${ }^{3}$ Collano AG, Sempach Station, 6203 Neuenkirch, Switzerland.

Received: 22 April 2020 Accepted: 18 September 2020 Published online: 29 September 2020

\section{References}

1. Dunky M, Niemz P (2002) Holzwerkstoffe und Leime (wood engineered products and adhesives). Springer, Berlin Heidelberg New York

2. Lehringer C, Gabriel J (2014) Review of recent research activities on onecomponent PUR-adhesives for engineered wood products. Materials and joints in timber structures. Springer, Heidelberg New York London, pp 405-420

3. Kägi A, Niemz P, Mandallaz D (2006) Einfluss der Holzfeuchte und ausgewählte technologische Parameter auf die Verklebung mit 1 K-PUR Klebstoffen unter extremen klimatischen Bedingungen (Influence of moisture content and selected technological parameters on the adhesion of one-part polyurethane adhesives under extreme climatical condition). Holz Roh Werkst 64:261-268

4. Clerc G, Lehmann M, Gabriel J, Salzgeber D, Pichelin F, Strahm T, Niemz P (2018) Improvement of ash (Fraxinus excelsior L.) bonding quality with one-component polyurethane adhesive and hydrophilic primer for loadbearing application. Int J Adhes Adhes 85:303-307

5. Follrich J, Vay O, Veigl S, Müller U (2010) Bond strength of end-grain joints and its dependence on surface roughness and adhesive spread. J Wood Sci 56:429-434

6. Luedtke L, Amen C, van Ofen A, Lehringer C (2015) 1C-PUR-bonded hardwoods for engineered wood products: influence of selected processing parameters. Eur J Wood Wood Prod 73:167-178

7. Themessel A, Lehmann M, Salzgeber D, Franke S (2018) Butt joint gluing of cross laminated timber. In World Conference on Timber Engineering, Seoul

8. Derikvand M, Ebrahimi G, Tajvidi M (2014) A feasibility study of using twocomponent polyurethane adhesive in constructing wooden structures. J For Res 25(2):477-482

9. Bockel S, Mayer I, Konnerth J, Harling S, Niemz P, Swaboda C, Beyer M, Harling S, Weiland G, Bieri N, Pichelin F (2018) Influence of wood extractives on two-component polyurethane adhesives for structural hardwood bonding. Int J Adhes 94(10):829-845

10. Bockel S, Mayer I, Konnerth J, Harling S, Niemz P, Swaboda C, Beyer M, Bieri N, Weiland G, Pichelin F (2019) The role of wood extractives in structural hardwood bonding and their influence on different adhesive systems. Int J Adhes Adhes. 91:43-53

11. Konnerth J, Kluge M, Schweizer G, Miljkovic M, Gindl-Altmutter W (2016) Survey of selected adhesive bonding properties of nine European softwood and hardwood species. Eur J Wood Prod 74:809-819

12. Yusof NM, Tahir P, Lee SH, Khan MA, James RMS (2019) Mechanical and physical properties of Cross-Laminated Timber made from Acacia mangium wood as function of adhesive types. J Wood Sci 20:1-11

13. Stöckel F, Konnerth J, Gindl-Altmutter W (2013) Mechanical properties of adhesives for bonding wood — a review. Int J Adhes Adhes 45:32-41

14. Clauß S, Allenspach K, Gabriel J, Niemz P (2011) Improving the thermal stability of once-component polyurethane adhesives by adding filler material. Wood Sci Technol 45:383-388 
15. Umemura K, Kawai S (2002) Effect of polyol on thermo-oxidative degradation of isocyanate resin for wood adhesives. J Wood Sci 48:25-31

16. Clauß S, Dikstra DJ, Gabriel J, Kläusler O, Matner M, Meckel W, Niemz P (2011) Influence of the chemical structure of PUR prepolymers on thermal stability. Int J Adhes Adhes 31:513-523

17. Harling S, Frei R; Weiland G (2016) Two component polyurethane adhesive for hardwood -influence of hardness of the adhesive towards the delamination process. In: in World Conference on Timber Engineering, Vienna

18. European Committee for Standardization, EN 302-1:2013-06 (2013) Adhesives for load-bearing timber structures — test methods - part 1: Determination of longitudinal tensile shear strength

19. European Committee for Standardization, EN 15425:2017-05 (2017) Adhesives-one component polyurethane (PUR) for load-bearing timber structures_classification and performance requirements

20. Owens D, Wendt R (1969) Estimation of the surface free energy of polymers. J Appl Polym Sci 13(8):1741-1747

21. German Institute for Standardization, DIN 55660-2:2011-12 (2011) Paints and varnishes — wettability — part 2: determination of free surface energy of solid surfaces by measuring the contact angle

22. German Institute for Standardization, DIN 55660-3:2011 (2011) Paints and varnishes-wettability-part 3: determination of the surface tension of liquids using the pendant drop method

23. European Committee for Standardization, EN ISO 527:2012-6 (2012) Plastics-determination of tensile properties_-part 1: general principles

24. Kläusler O, Clauß S, Lübke L, Trachsel J, Niemz P (2013) Influence of moisture on stress-strain behavior of adhesives used for structural bonding of wood. Int J Adhes Adhes 44:57-65

25. Gindl M, Reiterer A, Sinn G, Stanzl-Tschegg S (2004) Effects of surface ageing on wettability, surface chemistry, and adhesion of wood. Holz Roh Werkst 62:273-280
26. Yang X, Frazier CE (2016) Influence of organic fillers on surface tension of phenol-formaldehyde adhesives. Int J Adhes Adhes 66:160-166

27. Habenicht G (2009) Kleben-Grundlagen, Technologien, Anwendungen. Springer, Berlin-Heidelberg

28. Shi SQ, Gardener DJ (2001) Dynamic adhesive wettability of wood. Wood Fiber Sc 33(1):58-68

29. Stehr M, Gardener DJ, Walinder M (2001) Dynamic wettability of different machined wood surfaces. J Adhesion 76(3):185-200

30. Konnerth J, Jäger A, Eberhardsteiner J, Müller U, Gindl W (2006) Elastic properties of adhesive polymers. II. Polymer films and bond lines by means of nanoindentation. J Appl Polym Sci 102:1234-1239

31. Gindl W, Sretenovic A, Vincenti A, Müller U (2005) Direct measurement of strain distribution along a wood bond line. Part 2: effects of adhesive penetration on strain distribution. Holzforschung 59:307-310

32. Obersriebnig M, Konnerth J, Gindl-Altmutter W (2013) Evaluating fundamental position-dependent differences in wood cell wall adhesion using nanoindentation. Int J Adhes Adhes 40:129-134

33. Domka L (1994) Modification estimate of kaolin, chalk and precipitated calcium carbonate as plastomer and elastomer fillers. Colloid Polym Sci 272:1190-1202

34. Clauß S, Gabriel J, Karbach A, Matner M, Niemz P (2011) Influence of adhesive formulation on the mechanical properties and bonding performance if polyurethane prepolymers. Holzforschung 65:835-844

35. European Committee for Standardization, EN 14080:2013-09 (2013) Timber structures - glued laminated timber and glued solid timber-requirements

\section{Publisher's Note}

Springer Nature remains neutral with regard to jurisdictional claims in published maps and institutional affiliations.

\section{Submit your manuscript to a SpringerOpen ${ }^{\circ}$ journal and benefit from:}

- Convenient online submission

- Rigorous peer review

- Open access: articles freely available online

- High visibility within the field

- Retaining the copyright to your article

Submit your next manuscript at $\boldsymbol{\nabla}$ springeropen.com 